\title{
Effects of Ethanol and Naltrexone in a Model of Traumatic Brain Injury With Hemorrhagic Shock
}

\author{
Brian J. Zink, Carol H. Schultz, Susan A. Stern, Michelle Mertz, Xu Wang, Peter Johnston, and Richard F. Keep
}

\begin{abstract}
Background: Ethanol predisposes to traumatic injury and causes respiratory depression and cardiovascular compromise in models of traumatic brain injury (TBI) and hemorrhagic shock (HS). Endogenous opioids may play a role in ethanol intoxication and TBI. We studied the effects of ethanol and the opiate antagonist agent naltrexone (NTX) in a TBI/HS model.

Methods: Fifty-six pigs $(20 \mathrm{~kg})$ were anesthetized with isoflurane, intubated, instrumented, and subjected to fluid percussion TBI with concurrent $30 \mathrm{ml} / \mathrm{kg}$ hemorrhage over $30 \mathrm{~min}$. Seven groups were studied: Control, EtOH, NTX, INJ, INJ/EtOH, INJ/NTX, and INJ/EtOH/NTX. Ethanol ( $2 \mathrm{~g} / \mathrm{kg} \mathrm{IV)} \mathrm{was}$ given preinjury, followed by infusion of $0.4 \mathrm{~g} / \mathrm{kg} / \mathrm{hr}$. NTX $0.3 \mathrm{mg} / \mathrm{kg}$ intravenous was given $5 \mathrm{~min}$ postinjury. Parameters monitored for 120 min postinjury included minute ventilation $\left(\mathrm{V}_{\mathrm{E}}\right)$, blood pressure (MAP), cerebral perfusion pressure (CPP), cerebral venous lactate (Lac), arterial and cerebral venous blood gases, and brain tissue $\mathrm{P}_{\mathrm{ti}} \mathrm{O}_{2}$.

Results: Ethanol levels at injury were $220 \mathrm{mg} / \mathrm{dL}$. Ethanol-treated animals had depression of hypercapnic ventilatory response, which was reversed by administration of naltrexone. MAP and CPP were significantly lower in injured animals, but were not significantly improved by NTX. Cerebral venous $\mathrm{pH}$ was lower and lactate was higher in ethanol-treated animals.

Conclusion: In this TBI/HS model, NTX reverses ethanol-induced depression of hypercapnic ventilatory response but does not improve MAP, CPP, or metabolic acidosis. This suggests that the respiratory effects of ethanol in TBI, but not the hemodynamic effects, may be mediated by opiate receptor activation.

Key Words: Ethanol, Naltrexone, Brain Injury, Hemorrhagic Shock.
\end{abstract}

$\mathbf{E}^{1}$ THANOL INTOXICATION INCREASES the risk of traumatic brain injury (TBI). Up to $50 \%$ of TBI patients have a blood alcohol concentration over $0.1 \%$ at the time of injury (Jagger et al., 1984; Rimel et al., 1982; Zink and Maio, 1994). Clinical studies suggest that ethanol potentiates injury and may be associated with increased risk of early death or worse neurological outcome after TBI (Evans and Frick, 1993; Fell and Hertz, 1990; Gurney et al., 1992; Kraus et al., 1989; Waller et al., 1986; Zink et al., 1996). Some laboratory studies, using a variety of TBI models and species, have found increased mortality, worse neuropathology, and worse neurological outcome in ethanol-treated animals (Albin and Bunegin, 1986; Flamm et al., 1977; Franco et al., 1988; Shapira et al., 1997). Other TBI studies have not demonstrated a deleterious effect of ethanol in TBI (Masse et al., 2000; Zhang et al., 1999) while one study suggests a possible neuroprotective effect (Kelly et al., 1997). In previous studies from our laboratory, which

From the University of Michigan Emergency Medicine Research Laboratory (BJZ, CHS, SAS, MM, XW, PJ); and Crosby Neurosurgical Laboratory (RFK); Ann Arbor, Michigan.

Received for publication September 7, 2000; accepted April 2, 2001.

Supported by the NIAAA (5 K08 AA00184-03).

Reprint requests: Brian J. Zink, MD, University of Michigan, Department of Emergency Medicine, TC B1354, Ann Arbor, MI 48109-0303; Fax: 734936-9414; E-mail: bzink@umich.edu

Copyright () 2001 by the Research Society on Alcoholism. utilized a porcine fluid percussion model, we found early respiratory depression, decreased cerebral perfusion pressure (CPP), and decreased cerebral blood flow (CBF) in ethanol-treated animals (Zink and Feustel, 1995; Zink et al., 1993). When TBI is accompanied by hemorrhage, the deleterious effects of ethanol are magnified (Zink et al., 1998, 1999).

Endogenous opioids appear to modulate respiratory drive and activity (Mayfield and D'Alecy, 1992; Moss and Scarpelli, 1981; Petrozzino et al., 1993; Santiago and Edelman, 1985). Experimental evidence also suggests that endogenous opioids and opiate receptors may play a role in the pathogenesis of TBI (Hayes et al., 1983; Lyeth et al., 1995; McIntosh et al., 1987). Endogenous opioid concentrations are increased in brain tissue and cerebrospinal fluid after TBI in animal models, and opiate receptor antagonist agents have improved neurological outcome and reversed TBI-induced decreases in CBF and systemic hypotension (Armstead and Kurth, 1997; Hayes et al., 1983; Lyeth et al., 1995; McIntosh et al., 1987; Vink et al., 1990, 1991). Endogenous opioids have also been implicated in the pathogenesis of hemorrhagic shock (HS) (Gurll et al., 1981).

Some evidence suggests that the intoxicating and respiratory depressant effects of ethanol may be partially mediated by endogenous opioid activity or opiate receptor acti- 
vation. Ethanol increases endogenous opioid activity in human plasma, and naloxone has been reported to reverse ethanol-induced ventilatory depression in humans (Bar-or et al., 1982; Jeffcoate et al., 1979; Jeffreys et al., 1980; Michiels et al., 1983).

The possible relationship between acute ethanol intoxication, TBI, and endogenous opioid activity led to the following research question: Are the respiratory and cardiovascular depressant effects of ethanol in TBI and hemorrhage due to increased endogenous opioid activity and, if so, will administration of an opiate antagonist agent reverse some of the deleterious effects of ethanol? We tested the hypothesis that administration of naltrexone, a nonspecific opiate antagonist, will reverse ethanol-induced respiratory and cardiocirculatory depression in a porcine TBI and HS model.

\section{MATERIALS AND METHODS}

This study was approved by the University of Michigan Committee on the Use and Care of Animals. Animal care standards were in compliance with the Guide for the Care and Use of Laboratory Animals.

\section{Instrumentation}

The instrumentation procedure has been previously described in detail (Zink et al., 1998, 1999). Immature swine $(20 \mathrm{~kg})$ were sedated with ketamine, intubated, and anesthetized with isoflurane $(1.15 \%)$ at an $\mathrm{F}_{\mathrm{I}} \mathrm{O}_{2}$ of 0.28 . Femoral and carotid arteries and the femoral vein were accessed for blood pressure monitoring and blood withdrawal. A pulmonary artery thermodilution catheter was placed via the femoral vein for cardiac output monitoring. Brain instrumentation consisted of four craniotomies for placement of a fluid percussion bolt immediately anterior to and right of the bregma, a left intraventricular catheter, a sagittal sinus oximetric catheter, and a brain tissue metabolic probe (Paratrend 7; Diametrics, Inc., St. Paul, MN).

\section{Measurements}

After instrumentation, the following parameters were monitored continuously, with the exception of cardiac output, which was measured every $30 \mathrm{~min}$.

Hemodynamic parameters - mean arterial pressure (MAP), heart rate (HR), central venous pressure (CVP), cardiac output (CO), blood temperature.

Ventilatory parameters-ventilatory frequency $\left(\mathrm{V}_{\mathrm{F}}\right)$, tidal volume $\left(\mathrm{V}_{\mathrm{T}}\right)$, minute ventilation $\left(\mathrm{V}_{\mathrm{E}}\right)$, end tidal $\mathrm{CO}_{2}$ concentration, isoflurane concentration.

Brain physiologic parameters-intracranial pressure (ICP), cerebral perfusion pressure (CPP), cerebral venous oxygen saturation $\left(\mathrm{CvO}_{2}\right)$, brain temperature, brain tissue $\mathrm{pH}, \mathrm{PCO}_{2}, \mathrm{PO}_{2}$.

Hypercapnic respiratory response was assessed at specific time points by recording the above ventilatory measurements, infusing $5 \% \mathrm{CO}_{2}$ into the ventilatory circuit for $5 \mathrm{~min}$, and then repeating the measurements.

Metabolic parameters that were sampled and measured at specific time points included arterial blood gases, cerebral venous blood gases, blood sodium, potassium, chloride, calcium, bicarbonate, glucose and lactate concentrations, and serum ethanol levels.

\section{Interventions}

Animals in the injury groups received a concurrent fluid percussion brain injury and hemorrhage. Animals in the noninjury groups received full instrumentation and craniotomy procedures, but were not subjected to injury. The fluid percussion injury (FPI) has been previously described (Zink and Feustel, 1995; Zink et al., 1993). This type of injury is considered a midline model of FPI. The target brain injury was 3.2 atmospheres, which is felt to simulate severe brain injury in humans. Hemorrhage consisted of the removal of $30 \mathrm{ml} / \mathrm{kg}$ of blood via the femoral artery catheter over $30 \mathrm{~min}$ in a graded fashion with a computer-driven roller pump, as previously described (Zink et al., 1998). Animals in groups that received ethanol were administered an intravenous loading dose of $2 \mathrm{~g} / \mathrm{kg}$ over $25 \mathrm{~min}$, followed by a maintenance infusion of $0.4 \mathrm{~g} / \mathrm{kg} / \mathrm{hr}$. Nonethanol animals received an equal loading volume and infusion of intravenous normal saline. Animals in the naltrexone groups were administered 0.2 $\mathrm{mg} / \mathrm{kg}$ intravenously at $5 \mathrm{~min}$ postinjury.

\section{Experimental Groups}

Seven experimental groups were studied, with the following interventions:

CONTROL-instrumentation only $(n=4)$

EtOH-instrumentation and ethanol $(n=8)$

NTX-instrumentation and naltrexone $(n=4)$

INJ_brain injury and shock $(n=10)$

INJ/EtOH—brain injury, shock, ethanol $(n=10)$

INJ/NTX - brain injury, shock, naltrexone $(n=10)$

INJ/EtOH/NTX - brain injury, shock, ethanol, naltrexone $(n=10)$

After instrumentation and administration of ethanol or placebo normal saline, animals were monitored for $60 \mathrm{~min}$. Preinjury measurements were obtained, and the injury (TBI and hemorrhagic shock) was given at time point 0 . Animals were monitored without fluid resuscitation for $120 \mathrm{~min}$ postinjury, and full measurements, including hypercapnic respiratory response, were obtained at times 15, 45, 60, 90, and $120 \mathrm{~min}$. Animals that experienced apnea after injury received bag-valve assisted ventilation starting at $1 \mathrm{~min}$ postinjury. Animals with persistent apnea were placed on a ventilator, with $\mathrm{PaCO}_{2}$ maintained at 45 torr, and $\mathrm{PaO}_{2}$ maintained at 120-150 torr, and were administered the hypercapnic respiratory challenge at all time points. If the animal remained apneic, with no response to hypercapnia, the animal was recorded as being on the ventilator, but minute ventilation and the hypercapnic ventilatory data for that time point were not used in the statistical analysis.

\section{DATA ANALYSIS}

Group means and standard deviations were calculated for all measurements and time points. Statistical analysis was performed using analysis of variance (ANOVA) with Tukey post hoc test for intergroup comparisons and repeated-measures ( $\mathrm{rm}$ ) ANOVA for comparison at multiple time points. For most statistical analyses, the noninjured groups were compared separately from the injured groups. A $p$ value of 0.05 was considered statistically significant. A power analysis performed prior to the investigation determined that 10 animals would be needed in the injury groups to provide a power of greater than 0.80 with the following assumptions: an effect size of 2 liters/min for minute ventilation and the hypercapnic ventilatory difference; standard deviations of 1.5 for minute ventilation and 2.0 for the hypercapnic difference; and an alpha error of 0.05 .

\section{RESULTS}

\section{Baseline Characteristics}

Fifty-six experiments were performed, with 4 animals in the SHAM and NTX groups, 8 animals in the EtOH group, and 10 animals each in the four injury groups. With the exception of mean arterial pressure (MAP) and cerebral perfusion pressure (CPP), which were significantly lower in the groups that received ethanol, groups were well matched at time 0 in terms of weight, hemodynamic parameters, and metabolic parameters, and the measured brain injury (Ta- 
Table 1. Characteristics of the Injury Groups at Time Zero

\begin{tabular}{|c|c|c|c|c|c|}
\hline Parameter & INJ $n=10$ & INJ/ETOH $n=10$ & INJ/NTX $n=10$ & INJ/ETOH/NTX n $=10$ & $p=($ ANOVA $)$ \\
\hline Weight (kg) & $20(2)$ & $19(2)$ & $20(1)$ & $20(1)$ & 0.31 \\
\hline$V_{E}(L / m i n)$ & $6.3(1.0)$ & $5.7(1.6)$ & $5.8(0.9)$ & $7.1(1.7)$ & 0.104 \\
\hline $\mathrm{MAP}(\mathrm{mmHg})$ & $88(14)$ & $79(11)$ & $91(11)$ & $72(8)$ & 0.003 \\
\hline $\mathrm{CPP}(\mathrm{mmHg})$ & $75(13)$ & $68(12)$ & $74(9)$ & $59(6)$ & 0.005 \\
\hline $\mathrm{CO}(\mathrm{L} / \mathrm{min})$ & $3.7(0.6)$ & $3.6(0.8)$ & $3.4(0.8)$ & $3.7(1.0)$ & 0.73 \\
\hline Brain Temp $\left({ }^{\circ} \mathrm{C}\right)$ & $36.9(0.9)$ & $37.1(0.6)$ & $36.9(0.5)$ & $36.4(0.5)$ & 0.21 \\
\hline Injury (atm) & $3.4(0.4)$ & $3.1(0.4)$ & $3.2(0.4)$ & $3.2(0.3)$ & 0.45 \\
\hline
\end{tabular}

Temp $=$ temperature, $\mathrm{CO}=$ cardiac output. Numbers are means with standard deviations in parentheses.

Table 2. Postinjury Physiological Changes in the Injury Groups

\begin{tabular}{|c|c|c|c|c|c|}
\hline Parameter & INJ $n=10$ & INJ/ETOH n $=10$ & INJ/NTX $n=10$ & INJ/ETOH/NTX n $=10$ & $p$ \\
\hline Apnea at injury (\#) & 7 & 8 & 7 & 8 & 0.91 \\
\hline Apnea Postinjury (\#) & 5 & 5 & 2 & 4 & 0.49 \\
\hline \multicolumn{6}{|l|}{$\mathrm{HR}(\mathrm{bpm})$} \\
\hline $45 \min$ & $199(28)$ & $201(20)$ & $223(13)$ & $216(33)$ & 0.14 \\
\hline $120 \mathrm{~min}$ & $200(19)$ & $200(33)$ & $226(20)$ & $208(29)$ & \\
\hline \multicolumn{6}{|l|}{$\mathrm{CO}(\mathrm{L} / \mathrm{min})$} \\
\hline $45 \min$ & $1.97(0.46)$ & $1.89(0.65)$ & $2.05(0.71)$ & $2.04(0.54)$ & 0.98 \\
\hline $120 \mathrm{~min}$ & $2.06(0.56)$ & $2.06(0.64)$ & $2.19(0.66)$ & $2.08(0.55)$ & \\
\hline \multicolumn{6}{|l|}{$\mathrm{MAP}(\mathrm{mmHg})$} \\
\hline $45 \mathrm{~min}$ & $52(14)$ & $62(13)$ & $68(9)$ & $56(17)$ & 0.007 \\
\hline $120 \mathrm{~min}$ & $52(14)$ & $52(15)$ & $65(7)$ & $45(15)$ & \\
\hline \multicolumn{6}{|l|}{ ICP (mmHg) } \\
\hline $15 \min$ & $21(8)$ & $16(12)$ & $17(7)$ & $20(8)$ & 0.51 \\
\hline $120 \mathrm{~min}$ & $15(6)$ & $13(6)$ & $19(5)$ & $16(9)$ & \\
\hline
\end{tabular}

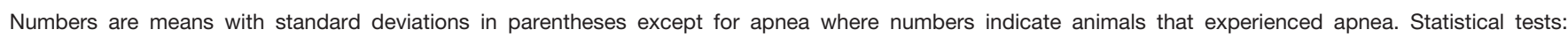
Kruskall-Wallis for apnea, and repeated measures ANOVA for other comparisons. HR, heart rate; CO, cardiac output; ICP, intracranial pressure.

ble 1). Mean ethanol levels were not significantly different between the INJ/EtOH and the INJ/EtOH/NTX groups at any time point (Table 3). Mean ethanol levels were lower in the EtOH group when compared with the INJ/EtOH and $\mathrm{INJ} / \mathrm{EtOH} / \mathrm{NTX}$ groups, but the difference was significant only at the 120 min time point $(p=0.035$, ANOVA)(Table 4).

\section{Respiratory Response and Survival}

Fluid percussion brain injury produced immediate, but transient, apnea of greater than 1-minute duration in at least $70 \%$ of the animals in each of the injury groups. During the postinjury period (after the 15 min time point), at least $40 \%$ of the animals in the INJ, INJ/EtOH, and $\mathrm{INJ} / \mathrm{EtOH} / \mathrm{NTX}$ groups had apneic periods of greater than $5 \mathrm{~min}$ that required mechanical ventilation for at least a portion of the experiment, compared with $20 \%$ of the animals in the INJ/NTX group ( $p=0.49$, Kruskal-Wallis test)(Table 2). Two animals in the INJ/EtOH group died prematurely (at 40 and 45 min postinjury) and one animal in the INJ/EtOH/NTX group died prematurely at $66 \mathrm{~min}$ postinjury. All of the animals in the other groups survived through 120 min.

Minute ventilation and the hypercapnic ventilatory response were lowest in the $\mathrm{INJ} / \mathrm{EtOH}$ group throughout the postinjury period when compared with the INJ, INJ/NTX, and $\mathrm{INJ} / \mathrm{EtOH} / \mathrm{NTX}$ groups $(p=0.097, \mathrm{rm}$ ANOVA for minute ventilation; $p=0.003$, rm ANOVA for hypercapnic ventilatory response). The highest postinjury minute ventilation occurred in the INJ/EtOH/NTX group, and the highest hypercapnic respiratory response occurred in the INJ/NTX group (Figs. 1 and 2). In the noninjury groups, neither ethanol nor naltrexone had significant effects on ventilation, although the numbers in these groups were small (Table 4).

\section{Hemodynamic Response}

MAP, CPP, and cardiac output fell significantly, and heart rate increased significantly after injury. In comparing MAP and CPP in the four injury groups, significant differences were found for MAP ( $p=0.007$, rm ANOVA) and for CPP ( $p=0.017$, rm ANOVA). (Table 2 and Figure 3 provide details.) Mean MAP and CPP values were highest in the INJ/NTX group and lowest in the INJ/EtOH/NTX group. On post hoc testing, there were significant differences in MAP and CPP between the INJ/NTX and INJ/ EtOH/NTX groups, but not between other groups (Table 2, Fig. 3). Heart rate increased ( $p=0.005$, rm ANOVA) and cardiac output decreased ( $p<0.001$, rm ANOVA) in response to injury but were not significantly different among the four injury groups during the postinjury period (Table 2). Intracranial pressure (ICP) increased briefly after fluid percussion TBI, and mean values were higher at time points 15 through 120 in the injured, compared with noninjured, animals but not to a significant degree. No significant differences in ICP were found among the four injury groups (Table 2). In the noninjury groups, ICP was significantly higher in the NTX group, and there was a trend toward higher MAP in the NTX group (Table 4). 


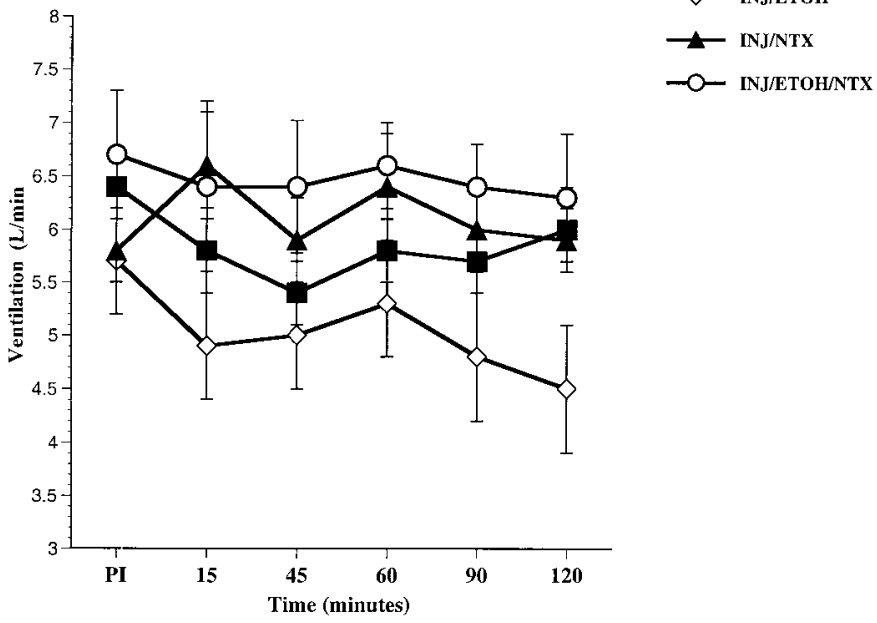

Fig. 1. Minute ventilation in the injury groups. Numbers are means with standard errors. Comparison of all groups $(p=0.097$, $(r m)$ ANOVA). Comparison of INJ/EtOH and INJ groups ( $p=0.139$, rm ANOVA). Comparison of INJ/EtOH and INJ/EtOH/NTX groups ( $p=0.054$, rm ANOVA). Rm, repeated measures.

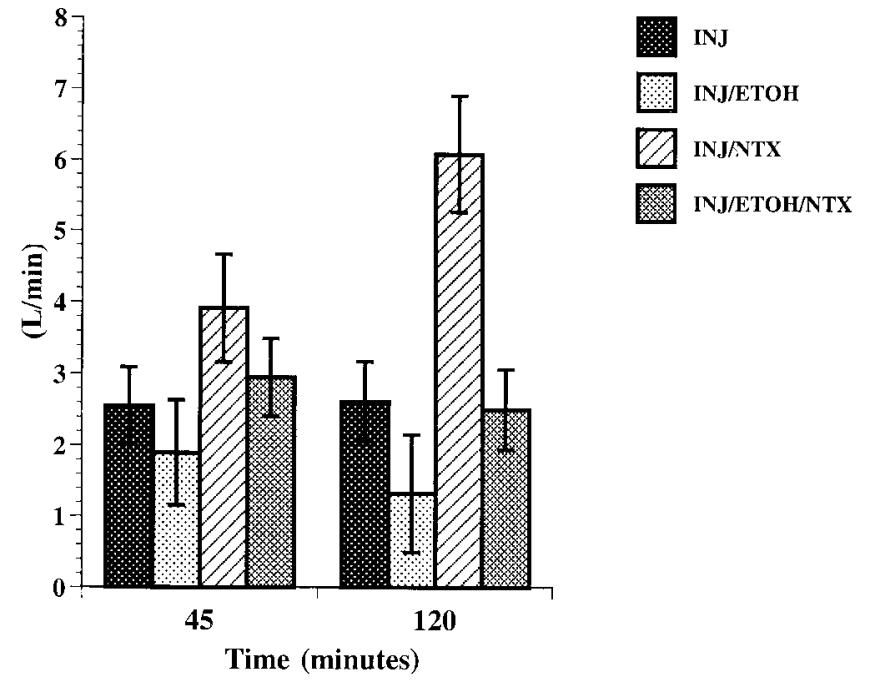

Fig. 2. Hypercapnic ventilatory response in the injury groups. Numbers are mean increase in minute ventilation after $5 \mathrm{~min}$ of hypercapnia, with standard errors. Comparison of all groups $(p=0.003, \mathrm{rm}$ ANOVA). Comparison of INJ/ EtOH and INJ groups ( $p=0.328$, rm ANOVA). Comparison of INJ/EtOH and INJ/EtOH/NTX groups $(p=0.19$, rm ANOVA). Rm, repeated measures.

\section{Metabolic Response}

Brain tissue oxygen fell significantly after injury $(p<0.001$, rm ANOVA). In the injury groups, brain tissue oxygen was consistently highest in the INJ/EtOH/NTX group, although values were highly variable ( $p=0.015, \mathrm{rm}$ ANOVA). Brain tissue probe data were not gathered in the EtOH group (Tables 3 and 4). Brain tissue $\mathrm{pH}$ also fell from a mean of 7.10 preinjury to a mean of 6.90 after injury but, due to high standard deviations, was not significantly different between the injured and noninjured groups $(p=0.121$, rm ANOVA)(Table 3). Brain tissue $\mathrm{CO}_{2}$ tended to increase after injury but the differences were not significant $(p=0.180, \mathrm{rm}$ ANOVA).

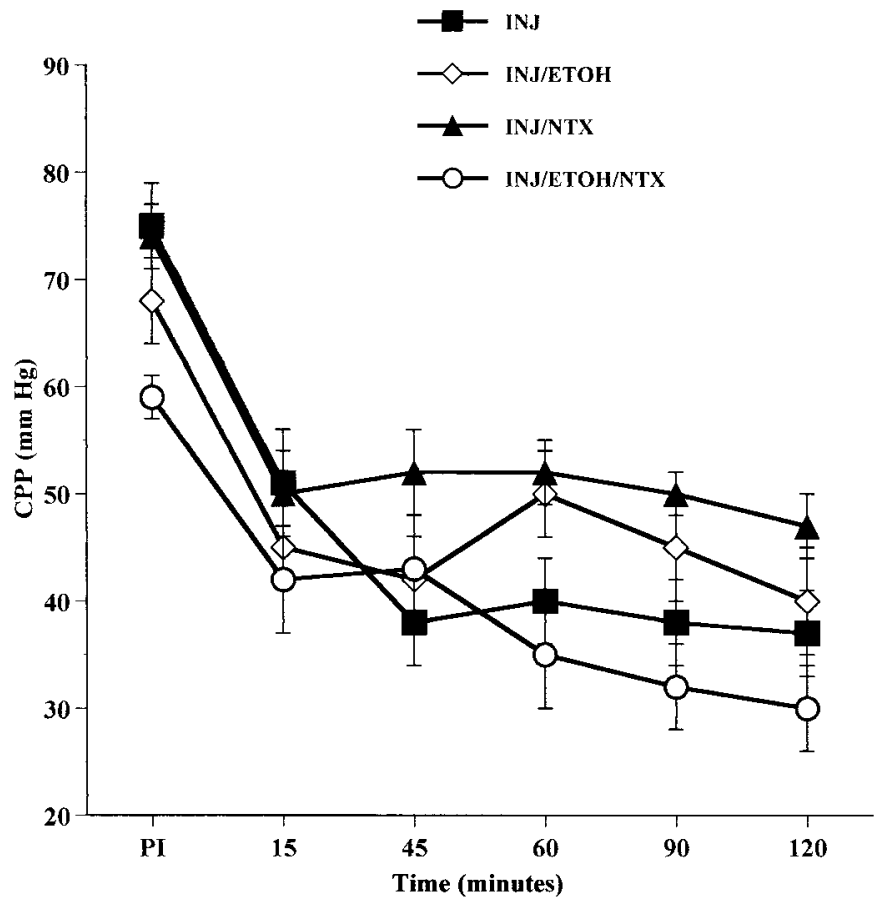

Fig. 3. Cerebral perfusion pressure in the injury groups. Numbers are means with standard errors. Comparison of all groups ( $p=0.017$, rm ANOVA). Rm, repeated measures.

Other metabolic parameters changed after injury in a manner similar to what has been previously reported in this model. In noninjured animals, ethanol administration was associated with higher cerebral venous lactate concentrations $(p=0.04)$, rm ANOVA)(Table 4). In injured animals, cerebral venous and arterial blood lactate levels rose and were highest in ethanol-treated animals $(p=0.153$ for arterial lactate, and $p=0.147$ for cerebral venous lactate, rm ANOVA). Cerebral venous $\mathrm{pH}$ was significantly lower in the INJ/EtOH and INJ/EtOH/NTX groups when compared with the nonethanol, injured groups after injury ( $p=$ $0.012, \mathrm{rm}$ ANOVA). Serum bicarbonate concentration also fell significantly after injury ( $p=0.001, \mathrm{rm}$ ANOVA) for all groups. In the injury groups, serum bicarbonate was also lowest in the ethanol-treated animals $(p=0.109$, rm ANOVA)(Table 3). Cerebral venous oxygen saturation fell significantly after injury ( $p<0.001$, rm ANOVA) but was not different between injury groups $(p=0.709$, rm ANOVA)(Table 3). Hemoglobin decreased in injured animals when compared with control groups $(p=0.07, \mathrm{rm}$ ANOVA), but was not significantly different between the injured groups $(p=0.20$, rm ANOVA)(Table 3). Cerebral venous blood glucose levels rose in response to injury ( $p=$ 0.062 , rm ANOVA) but were not different between the injury groups $(p=0.302, \mathrm{rm}$ ANOVA $)$ (Table 3$)$.

\section{DISCUSSION}

In this anesthetized, porcine model of fluid-percussion brain injury and graded hemorrhagic shock, acute ethanol 
Table 3. Postinjury Metabolic Changes in the Injury Groups

\begin{tabular}{|c|c|c|c|c|c|}
\hline Parameter & $\mathrm{INJ} n=10$ & INJ/ETOH $n=10$ & INJ/NTX $n=10$ & INJ/ETOH/NTX n $=10$ & $p$ \\
\hline \multicolumn{6}{|l|}{ Ethanol (mg/dL) } \\
\hline $60 \mathrm{~min}$ & & $239(66)$ & & $237(24)$ & 0.94 \\
\hline $120 \mathrm{~min}$ & & $256(47)$ & & $229(16)$ & 0.15 \\
\hline \multicolumn{6}{|l|}{$\mathrm{CvO}_{2}$ (\%sat) } \\
\hline $15 \mathrm{~min}$ & $51(17)$ & $53(10)$ & $50(15)$ & $58(6)$ & \multirow[t]{2}{*}{0.71} \\
\hline $120 \mathrm{~min}$ & $53(16)$ & 49 (18) & 46 (13) & $51(3)$ & \\
\hline \multicolumn{6}{|l|}{$\mathrm{PaCO}_{2}$ (torr) } \\
\hline $45 \mathrm{~min}$ & $39(8)$ & $39(8)$ & $37(7)$ & $38(6)$ & \multirow[t]{2}{*}{0.39} \\
\hline $120 \mathrm{~min}$ & $41(11)$ & $47(9)$ & $40(7)$ & $41(10)$ & \\
\hline \multicolumn{6}{|c|}{ Lactate cv (mg/dL) } \\
\hline $45 \mathrm{~min}$ & $3.3(1.4)$ & $4.7(2.2)$ & $3.7(1.6)$ & $4.8(0.8)$ & \multirow[t]{2}{*}{0.15} \\
\hline $120 \mathrm{~min}$ & $4.5(2.7)$ & $5.3(1.5)$ & $5.4(3)$ & $7.4(1.1)$ & \\
\hline \multicolumn{6}{|c|}{ Glucose cv (mg/dL) } \\
\hline $45 \min$ & $145(52)$ & $160(54)$ & $180(69)$ & $235(88)$ & \multirow[t]{2}{*}{0.30} \\
\hline $120 \mathrm{~min}$ & $137(50)$ & $145(65)$ & $170(51)$ & $175(95)$ & \\
\hline \multicolumn{6}{|l|}{$\mathrm{pH} \mathrm{cv}$ (units) } \\
\hline $45 \mathrm{~min}$ & $7.30(0.07)$ & $7.20(0.13)$ & $7.29(0.04)$ & $7.23(0.04)$ & \multirow[t]{2}{*}{0.01} \\
\hline $120 \mathrm{~min}$ & $7.26(0.06)$ & $7.17(0.09)$ & $7.23(0.07)$ & $7.16(0.02)$ & \\
\hline \multicolumn{6}{|l|}{$\mathrm{HCO} 3(\mathrm{mmol} / \mathrm{L})$} \\
\hline $45 \mathrm{~min}$ & $25(5)$ & $21(5)$ & $22(3)$ & $21(3)$ & \multirow[t]{2}{*}{0.11} \\
\hline $120 \mathrm{~min}$ & $23(5)$ & $21(4)$ & $21(4)$ & $20(4)$ & \\
\hline \multicolumn{6}{|c|}{ Hemoglobin $(g / d L)$} \\
\hline $15 \mathrm{~min}$ & $10.0(0.1)$ & $10.4(1.6)$ & $11.0(1.0)$ & $11.2(1.1)$ & \multirow[t]{2}{*}{0.20} \\
\hline $120 \mathrm{~min}$ & $9.3(0.8)$ & $9.8(1.6)$ & $10.2(0.6)$ & $10.6(1.2)$ & \\
\hline \multicolumn{6}{|l|}{ Brain pH (units) } \\
\hline $15 \mathrm{~min}$ & $6.86(0.22)$ & $6.86(0.38)$ & $6.96(0.14)$ & $6.85(0.34)$ & \multirow[t]{2}{*}{0.45} \\
\hline $120 \mathrm{~min}$ & $6.80(0.38)$ & $6.88(0.36)$ & $6.93(0.20)$ & $6.91(0.23)$ & \\
\hline \multicolumn{6}{|l|}{ Brain $\mathrm{PO}_{2}$ (torr) } \\
\hline $15 \min$ & $9(11)$ & $10(11)$ & $8(9)$ & $18(18)$ & \multirow[t]{2}{*}{0.02} \\
\hline $120 \mathrm{~min}$ & $10(13)$ & $5(7)$ & $3(4)$ & $22(17)$ & \\
\hline
\end{tabular}

Numbers are means with standard deviations in parentheses. cv, cerebral venous; art, arterial; brain, brain tissue. Statistical tests, ANOVA or repeated measures ANOVA.

intoxication impaired the hypercapnic ventilatory response, and this effect was reversed by the administration of the nonselective opiate receptor antagonist naltrexone. Ethanol levels at the time of injury were similar to levels that are commonly reported in intoxicated humans who suffer traumatic brain injury (Gurney et al., 1992; Jagger et al., 1984). The cardiovascular effects of ethanol and naltrexone in this model were less distinct. Postinjury cardiovascular compromise was not as pronounced in ethanol-treated animals as in our previous studies (Zink et al., 1998, 1999). In this study, ethanol-treated, injured animals had lower MAP and CPP that was comparable to other injured animals, but the $\mathrm{INJ} / \mathrm{EtOH}$ group differed in the response to naltrexone. Naltrexone administration increased MAP and CPP in nonethanol injured animals but did not improve hemodynamics in ethanol-treated injured animals. Naltrexone also did not reverse impairments in cerebral metabolic parameters.

The ventilatory response to TBI and HS in this study was similar to what has been reported in our previous studies. (Zink and Feustel, 1995; Zink et al., 1998). Ethanol caused a modest decrease in minute ventilation prior to injury that is accentuated after TBI and shock. Ventilatory drive, as assessed by exposure to hypercapnia, was significantly reduced after TBI/HS in ethanol-treated animals. The effects of ethanol and injury on hypercapnic ventilatory drive were greater than on minute ventilation.

Inadequate ventilation and hypoxemia may contribute to secondary brain injury after TBI. The importance of ven- tilatory depression has been demonstrated in clinical TBI studies that have shown increased morbidity and mortality in patients who have early hypoxemia (Atkinson, 2000; Chestnut et al., 1993; Winchell and Hoyt, 1997). In this study, apneic animals were supported with mechanical ventilation and did not become hypoxemic. Clinical studies lend some support to the idea that acute ethanol intoxication in the setting of TBI can cause ventilatory depression. One study found that intoxicated patients with TBI were significantly more likely to require endotracheal intubation in the field or emergency department and to develop respiratory distress during hospitalization (Gurney et al., 1992). A number of studies have found that alcoholintoxicated motor vehicle crash victims are more likely to die in the early postinjury period than nonintoxicated victims, and it is speculated that respiratory depression may contribute to early death (Fell and Hertz, 1990; Zink et al., 1996).

Although it is known that endogenous opiate peptides and opiate receptor agonist drugs induce ventilatory depression, the role of endogenous opioids in the control of ventilation is felt to be more modulatory than regulatory (Santiago and Edelman, 1985). However, some investigators believe that, in states of increased stress, including trauma, endogenous opioids may play a larger role in the regulation of respiration (Mayfield and D'Alecy, 1992; Moss and Scarpelli, 1981; Petrozzino et al., 1993; Santiago and Edelman, 1985). Ethanol causes dose-dependent respiratory depression, and some previous studies suggest that 
Table 4. Selected Physiological and Metabolic Data for the Control Groups

\begin{tabular}{|c|c|c|c|c|}
\hline Parameter & SHAM $n=4$ & NTX $n=4$ & $\mathrm{ETOH} n=8$ & $p$ \\
\hline \multicolumn{5}{|l|}{ Ethanol (mg/dL) } \\
\hline $60 \min$ & & & $198(11)$ & \\
\hline $120 \mathrm{~min}$ & & & $213(20)$ & \\
\hline \multicolumn{5}{|l|}{$V_{E}(L / m i n)$} \\
\hline $60 \min$ & $7.8(1.4)$ & $7.7(1.2)$ & $6.3(0.6)$ & 0.36 \\
\hline $120 \mathrm{~min}$ & $7.3(1.4)$ & $5.9(1.4)$ & $5.3(0.5)$ & \\
\hline \multicolumn{5}{|l|}{ ICP $(\mathrm{mm} \mathrm{Hg})$} \\
\hline $60 \mathrm{~min}$ & $12(6)$ & $19(5)$ & $8(5)$ & 0.01 \\
\hline $120 \mathrm{~min}$ & $14(6)$ & 22 (5) & $10(5)$ & \\
\hline \multicolumn{5}{|l|}{ CPP $(\mathrm{mm} \mathrm{Hg})$} \\
\hline $60 \mathrm{~min}$ & $57(14)$ & $70(13)$ & $65(8)$ & 0.54 \\
\hline $120 \mathrm{~min}$ & $58(13)$ & $50(17)$ & $61(12)$ & \\
\hline \multicolumn{5}{|l|}{$\mathrm{CvO}_{2}$ sat (\%) } \\
\hline $60 \min$ & 78 (5) & $82(7)$ & $85(3)$ & 0.20 \\
\hline $120 \mathrm{~min}$ & 76 (5) & $77(11)$ & $82(10)$ & \\
\hline \multicolumn{5}{|c|}{ Lactate cv (mg/dL) } \\
\hline $60 \min$ & $1.8(0.6)$ & $2.5(0.6)$ & $3.5(1.5)$ & 0.04 \\
\hline $120 \mathrm{~min}$ & $1.8(0.5)$ & $2.1(0.9)$ & $3.9(2.0)$ & \\
\hline \multicolumn{5}{|c|}{ Glucose cv (mg/dL) } \\
\hline $60 \mathrm{~min}$ & $114(21)$ & $113(14)$ & $109(38)$ & 0.74 \\
\hline $120 \mathrm{~min}$ & 95 (13) & $109(9)$ & $108(30)$ & \\
\hline \multicolumn{5}{|c|}{ Hemoglobin (g/dL) } \\
\hline $60 \mathrm{~min}$ & $10.8(0.6)$ & $11.5(1.3)$ & $10.3(1.8)$ & 0.80 \\
\hline $120 \mathrm{~min}$ & $10.8(1.2)$ & $11.6(0.8)$ & $11.3(1.7)$ & \\
\hline \multicolumn{5}{|l|}{ Brain $\mathrm{PO}_{2}$ (torr) } \\
\hline $15 \min$ & $30(14)$ & $45(16)$ & NA & \\
\hline $120 \mathrm{~min}$ & $20(15)$ & $44(13)$ & NA & \\
\hline
\end{tabular}

Numbers are means with standard deviations in parentheses. cv, cerebral venous; art, arterial; brain, brain tissue. NA, data not available, probe not used in the ETOH group. Statistical tests, ANOVA or repeated measures ANOVA.

endogenous opioids may play a role (Sahn et al., 1975). Michiels et al. (1983) found that ethanol intoxication to a mean level of $130 \mathrm{mg} / \mathrm{dL}$ in humans decreased hypercapnic ventilatory response but did not significantly affect resting ventilation. Administration of the opiate antagonist naloxone reversed the decrease in hypercapnic response (Michiels et al., 1983). Bar-or et al. (1982) reported that plasma beta-endorphins were significantly elevated in human volunteers with acute ethanol intoxication. Clinical reports have suggested that naloxone inconsistently reverses ethanol-induced coma (Jeffcoate et al., 1979; Jeffreys et al., 1980). Despite its widespread use in oral form to reduce alcohol craving in alcohol-dependent humans, little is known about the ventilatory and hemodynamic effects of naltrexone in traumatic injury.

Blood and brain acidosis are felt to play an integral role in the control of ventilation (Sahn et al., 1975; Santiago et al., 1985). In this study, we found that ethanol significantly reduced cerebral venous blood $\mathrm{pH}$ and, in previous studies, we have found elevated blood and brain lactate concentrations in ethanol-treated animals after TBI (Zink et al., 1999). Theoretically, an ethanol-induced decrease in blood $\mathrm{pH}$ should further stimulate ventilation, but this was not observed, suggesting that the normal homeostatic control of ventilation is disrupted in the presence of ethanol. In the current investigation, brain tissue $\mathrm{pH}$ fell after TBI but was not significantly lower in ethanol-treated animals. The reliability of the monitoring device is called into question due to large variance in the measurements. Our findings contrast with a previous study that found an increase in intra- cellular brain $\mathrm{pH}$ (measured by Phosporus-31 NMR) in ethanol-intoxicated rats subjected to lateral fluid percussion TBI (Yamakami et al., 1995).

Endogenous opioids may play a role in the cardiocirculatory response to TBI and hemorrhage. A number of investigations since the 1980s have defined the role of endogenous opioids in contributing to hemodynamic compromise during HS, and many found that opiate antagonist agents could improve hemodynamics and outcome in a variety of shock models (Curtis and Lefer, 1980; Gurll et al., 1981, 1982; Komjati et al., 1997; Lightfoot et al., 2000; McIntosh et al., 1985, 1986; Reynolds et al., 1989; Salerno et al., 1981; Wichmann et al., 2000). Similar findings have been described with brain injury models. Hayes et al. (1983) found that naloxone significantly reversed systemic hypotension and the reduction in cerebral perfusion pressure in cats with fluid percussion brain injury. McIntosh et al. (1987) found that endogenous opioids contribute to systemic and cerebral vascular alterations after brain injury. In a newborn pig model of fluid percussion brain injury, naloxone was found to blunt the decrease in cerebral blood flow that was seen with brain injury (Armstead and Kurth, 1994). In the only other study to report the use of opiate antagonists in a TBI and HS model, DeWitt et al. (1997) found that the $\kappa$ opiate antagonist agent, nalmefene, restored cerebral blood flow and oxygen delivery in cats. Previous studies in hemorrhagic shock models without brain injury suggest that opiate antagonists improve hemodynamics by augmenting the release of catecholamines and by increasing peripheral vascular resistance (McIntosh et al., 1985; Toth et al., 1986). Ethanol has been found to increase norepinephrine levels in trauma patients and humans subjected to mild hemorrhage, but the opposite effect has been seen in humans with severe brain injury (Newsome, 1988; Woolf et al., 1990).

Our results support previous studies suggesting that opiate antagonists can improve hemodynamics and cerebral perfusion in TBI and HS, but this potentially beneficial effect was not observed in ethanol-treated animals. This is of potential clinical significance because the presence of hypotension and reduced cerebral blood flow are predictive of poor outcome from TBI (Chestnut et al., 1993, 1998; Dereeper et al., 1998; McMahon et al., 1999).

The findings of this study suggest that different biomolecular mechanisms are responsible for ethanol-induced ventilatory depression as compared with cardiocirculatory effects after TBI and HS. While the control of ventilation rests primarily in brain medullary respiratory neurons, the control of cardiovascular tone and cardiac contractility is accomplished with a more complex array of central nervous system and peripheral mechanisms. If the ventilatory depressant effects of ethanol in TBI are primarily mediated by endogenous opioids, they might be more easily reversed by naltrexone than cardiovascular effects that are only partially mediated by endogenous opioids.

A number of factors limit the interpretation of the results 
of this study. Although all animals were anesthetized with the same dose of isoflurane, it is not clear how isoflurane affects the ventilatory and cardiovascular responses to naltrexone. Only one dose of naltrexone was studied, and it is possible that a higher dose may have had more potent respiratory or cardiovascular effects. Another limitation is that endogenous opioids or opiate receptor activity were not measured. However, other studies using a similar model have demonstrated an elevation in endogenous opioids after TBI (McIntosh et al., 1987).

Ethanol appears to have harmful effects on the early physiologic response to traumatic brain injury, particularly when TBI is accompanied by hemorrhagic shock. This study found that ethanol-induced depression of hypercapnic ventilatory drive was reversed by the administration of naltrexone. Naltrexone increased postinjury blood pressure and cerebral perfusion pressure only in those animals that were not treated with ethanol. This suggests that the mechanisms that are responsible for ethanol-induced ventilatory depression in traumatic brain injury and hemorrhagic shock differ from those that control the cardiocirculatory response.

\section{REFERENCES}

Albin MS, Bunegin L (1986) An experimental study of craniocerebral trauma during ethanol intoxication. Crit Care Med 14:841-846.

Armstead WM, Kurth CD (1994) The role of opioids in newborn pig fluid percussion brain injury. Brain Res 660:19-26.

Atkinson JLD (2000) The neglected prehospital phase of head injury: Apnea and catecholamine surge. Mayo Clin Proc 75:37-47.

Bar-or D, Marx JA, Good J (1982) Breathlessness, alcohol and opiates (letter). N Engl J Med 306:1363-1364.

Chestnut RM, Gautille T, Blunt BA, Klauber MR, Marshall LF (1998) Neurogenic hypotension in patients with severe head injuries. J Trauma 44:958-964.

Chestnut RM, Marshall LF, Klauber MR, Blunt BA, Baldwin N, Eisenberg HM, Jane JA, Marmarou A, Foulkes MA (1993) The role of secondary brain injury in determining outcome from severe head injury. J Trauma 34:216-222.

Curtis MT, Lefer AM (1980) Protective actions of naloxone in hemorrhagic shock. Am J Physiol 239:H416-H421.

Dereeper E, Ciardelli R, Vincent JL (1998) Fatal outcome after polytrauma: Multiple organ failure or cerebral damage? Resuscitation 36: $15-18$.

Dewitt DS, Prough DS, Uchida T, Deal DD, Vines SM (1997) Effects of nalmefene, CG3703, tirilazad, or dopamine on cerebral blood flow, oxygen delivery, and electroencephalographic activity after traumatic brain injury and hemorrhage. J Neurotrauma 14:931-941.

Evans L, Frick MC (1993) Alcohol's effect on fatality risk from a physical insult. J Stud Alcohol 54:441-449.

Fell JC, Hertz ES (1990) The effects of blood alcohol concentration on time of death for fatal crash victims, in 34th Annual Proceedings: Association for the Advancement of Automotive Medicine. pp 69-81. Association for the Advancement of Automotive Medicine, Scottsdale, AZ.

Flamm ES, Demopoulos HB, Seligman ML, Tomasula JJ, De Crescito V, Ransohoff J (1977) Ethanol potentiation of central nervous system trauma. J Neurosurg 46:328-335.

Franco CD, Spillert CR, Spillert KR, Lazaro EJ (1988) Alcohol increases mortality in murine head injury. J Natl Med Assoc 80:63-65.
Gurll NJ, Reynolds DG, Vargish T, Lechner R (1982) Naltrexone improves survival rate and cardiovascular function in canine hemorrhagic shock. J Pharmacol Exp Ther 220:625-628.

Gurll NJ, Vargish T, Reynolds DG, Lechner RB (1981) Opiate receptors and endorphins in the pathophysiology of hemorrhagic shock. Surgery 89:364-369.

Gurney JG, Rivara FP, Mueller BA, Newell DWQ, Copass MK, Jurkovich GJ (1992) The effects of alcohol intoxication on the initial treatment and hospital course of patients with acute brain injury. J Trauma 33:709-713.

Hayes RL, Calinat BJ, Kulkarne P, Becker DP (1983) Effects of naloxone on systemic and cerebral responses to experimental concussive brain injury in cats. J Neurosurg 58:720-728.

Jagger J, Fife D, Vernberg K, Jane J (1984) Effect of alcohol intoxication on the diagnosis and apparent severity of brain injury. Neurosurgery 15:303-306.

Jeffcoate WJ, Cullen MH, Hastings AG, Walder CP (1979) Prevention of the effects of alcohol intoxication by naloxone. Lancet 1:1157-1159.

Jeffreys DB, Flanagan RJ, Volans GN (1980) Reversal of ethanol-induced coma with naloxone. Lancet 1:308-309.

Kelly DF, Lee SM, Pinanong PA, Hovda DA (1997) Paradoxical effects of acute ethanolism in experimental brain injury. J Neurosurg 86:876-882.

Komjati K, Sandor P, Sandor N, Szirmai L, H-Velkei M, Kovach AG (1997) Cerebrocortical and medullary blood flow changes after general opiate receptor blockade during hemorrhagic shock in cats. Shock 7:288-293.

Kraus JF, Morgenstern H, Fife D, Conroy C, Nourjah P (1989) Blood alcohol tests, prevalence of involvement, and outcomes following brain injury. Am J Public Health 79:294-299.

Lightfoot JT, Katz L, DeBate K (2000) Naloxone decreases tolerance to hypotensive, hypovolemic stress in healthy humans. Crit Care Med 28:684-691.

Lyeth BG, Jiang JY, Gong QZ, Hamm RJ, Young HF (1995) Effects of $\mathrm{Mu}$ opioid agonist and antagonist on neurological outcome following traumatic brain injury in the rat. Neuropeptides 29:11-19.

Masse J, Billings B, Dhillon HS, Mace D, Hicks R, Barron S, Kraemer PJ, Dendle P, Prasad RM (2000) Three months of chronic ethanol administration and the behavioral outcome of rats after lateral fluid percussion brain injury. J Neurotrauma 17:421-430.

Mayfield KP, D'Alecy LG (1992) Role of endogenous opioid peptides in the acute adaptation to hypoxia. Brain Res 582:226-231.

McIntosh TK, Hayes RL, DeWitt DS, Agura V, Faden AI (1987) Endogenous opioids may mediate secondary damage after experimental brain injury. Am J Physiol 253:E565-E574.

McIntosh TK, Palter M, Grasberger R, Vezina R, Gerstein L, Yeston N, Egdahl RH (1986) Endorphins in primate hemorrhagic shock: Beneficial action of opiate antagonists. J Surg Res 40:265-275.

McIntosh TK, Palter M, Grasberger R, Vezina R, Yeston NS, Egdahl RH (1985) Effect of an opiate antagonist (naloxone) and an agonist/antagonist (nalbuphine) in primate hemorrhagic shock: Relationship to catecholamine release. Circ Shock 17:313-325.

McMahon CG, Yates DW, Campbell FM, Hollis S, Woodford M (1999) Unexpected contribution of moderate traumatic brain injury to death after major trauma. J Trauma 47:891-895.

Michiels TM, Light RW, Mahutte CK (1983) Effect of ethanol and naloxone on control of ventilation and load perception. J Appl Physiol 55:929-934.

Moss IR, Scarpelli EM (1981) $\beta$-Endorphin central depression of respiration and circulation. J Appl Physiol 50:1001-1016.

Newsome HH (1988) Ethanol modulation of plasma norepinephrine response to trauma and hemorrhage. J Trauma 28:1-9.

Petrozzino JJ, Scardella AT, Edelman NH, Santiago TV (1993) Respiratory muscle acidosis stimulates endogenous opioids during inspiratory loading. Am Rev Respir Dis 147:607-615.

Reynolds DG, Gurll NJ, Holaday JW, Lechner RM (1989) The therapeutic efficacy of opiate antagonists in hemorrhagic shock. Resuscitation 18(2-3):243-251. 
Rimel R, Giordani B, Barth JT, Jane J (1982) Moderate head injury: Completing the clinical spectrum of brain trauma. Neurosurgery 11: 344-351.

Sahn SA, Lakshminarayan S, Pierson DJ, Weil JV (1975) Effect of ethanol on the ventilatory responses to oxygen and carbon dioxide in man. Clin Sci Mol Med 49:33-38.

Salerno TA, Milne B, Jhamandas KH (1981) Hemodynamic effects of naloxone in hemorrhagic shock in pigs. Surg Gynecol Obstet 152:773776.

Santiago TV, Edelman NH (1985) Opioids and breathing. J Appl Physiol 59:1675-1685.

Shapira Y, Lam AM, Paex A, Artru AA, Laohaprasit V, Donato T (1997) The influence of acute and chronic alcohol treatment on brain edema, cerebral infarct volume and neurological outcome following experimental head trauma in rats. J Neurosurg Anesthesiol 9:118-127.

Toth PD, Hamburger SA, Judy WV (1986) Hemodynamic effects of naloxone on hemorrhagic shock in the beagle. Circ Shock 20:35-42.

Vink R, McIntosh TK, Rhomhanyi R, Faden AI (1990) Opiate antagonist nalmefene improves intracellular Free $\mathrm{Mg}^{2+}$, bioenergetic state, and neurologic outcome following traumatic brain injury in rats. J Neurosci 10:3524-3530.

Vink R, Portoghese PS, Faden AI (1991) 75-Opioid antagonist improves cellular bioenergetics and recovery after traumatic brain injury. Am J Physiol 261:R1527-R1532.

Waller PF, Stewart JR, Hansen AR, Stutts JC, Popkin CL, Rodgman EA (1986) The potentiating effects of alcohol on driver injury. JAMA 256:1461-1466.

Wichmann MW, Zellweger R, Ayala A, Chaudry IH (2000) Effect of naloxone on immune responses after hemorrhagic shock. Crit Care Med 28:184-189.
Winchell RJ, Hoyt DB (1997) Endotracheal intubation in the field improves survival in patients with severe head injury. Arch Surg 132:592597.

Woolf PD, Cox C, Kelly M, McDonald JV, Hamill RW (1990) Alcohol intoxication blunts sympatho-adrenal activation following brain injury. Alcohol Clin Exp Res 14:205-209.

Yamakami I, Vink R, Faden A, Gennarelli TA, Lenkinski R, McIntosh TK (1995) J Neurosurg 82:813-821.

Zhang L, Maki A, Dhillon HS, Barron S, Clerici WJ, Hicks R, Kraemer PJ, Butcher J, Prasad RM (1999) Effects of six weeks of chronic ethanol administration on the behavioral outcome of rats after lateral fluid percussion brain injury. J Neurotrauma 16:243-254.

Zink BJ, Feustel PH (1995) Effects of ethanol on respiratory function in traumatic brain injury. J Neurosurg 82:822-828.

Zink BJ, Maio RF (1994) Alcohol use and trauma. Acad Emerg Med 1:171-173.

Zink BJ, Maio RF, Chen B (1996) Alcohol, central nervous system injury, and time to death in fatal motor vehicle crashes. Alcohol Clin Exp Res 20:1518-1522

Zink BJ, Schultz CH, Wang X, Mertz M, Stern SA, Betz AL (1999) Effects of ethanol on brain lactate in experimental traumatic brain injury with hemorrhagic shock. Brain Res 837:1-7.

Zink BJ, Sheinberg MA, Wang X, Mertz M, Stern SA, Betz AL (1998) Acute ethanol intoxication in a model of traumatic brain injury with hemorrhagic shock: Effects on early physiological response. J Neurosurg 89:983-990.

Zink BJ, Walsh RF, Feustel PJ (1993) Effects of ethanol in traumatic brain injury. J Neurotrauma 10:275-286. 